\title{
A Study on the Efficiency of Civil Pilots Training Bases in China
}

\author{
Xue Wang ${ }^{1, a}$ \\ ${ }^{1}$ College of Airport Engineering and Transportation Management \\ Civil Aviation Flight University of China \\ Guanghan, China \\ aJanewang0128@126.com
}

Keywords: Air transportation; Civil pilots; Training efficiency; Window-DEA

\begin{abstract}
The paper used Window-DEA combined with super-efficiency to analyze the efficiency of pilot training bases in China. Four bases in CAFUC were selected as the sample. The results showed that Base 1 had the most efficient and stable efficiency. The efficiency of Base 3 and Base 4 fluctuated significantly, which made the overall efficiency not stable.
\end{abstract}

\section{Introduction}

Civil aviation industry has experienced fast development around the world in recent years along with the recovery of world economics and the depreciation of fuel prices. The constant increase of market demand, technique progress, deregulation and liberalization to the air transport industry contributed to the enormous development. However China air transportation still faces the challenges of insufficient resource capacity and incremental demand growth. Among the challenges, pilot shortage has been regarded as the most serious problem faced by airlines in China. Flight training is the foundation of the aviation industry. To solve the problem of pilot shortage, it is essential to develop the training organizations' capacity. While airlines competing to improve the operational efficiency, flight training organizations are also paying attention to their training efficiency.

Stochastic Frontier Analysis (SFA) and Data Envelopment Analysis (DEA) are most frequently used methods to evaluate efficiency of airline industry. Based on the analysis of the panel data from American airlines, Cornwell, Schmidt and Sickles[1] (1990) suggested that the improvement of technique efficiency mainly attributes to the deregulation of industry. Schefczyk[2] (1993) used non-financial data to compare 15 airlines' efficiency by using DEA methods for the first time. Michaelides etc. [3] (2009) analyzed the efficiency of world's biggest 24 airlines and found similar results from SFA and DEA. Due to the lack of data, there is still no published bibliography studying on the efficiency of civil pilots training. Some research in China focused on the evaluation of training effects for pilot students and the safety condition of training, without referring to the evaluation of flight training bases' efficiency.

Although there are similarities of the operation modes between airlines and flight training institutions, the operating targets and producing features are significantly different. As a result, it is not valid to apply the evaluation methods and models for airlines directly into flight training bases. Considering the complexity of the problem due to the limited number of sample and enormous impacting factors, the paper use window DEA with super efficiency to analyze the comparable training efficiency based on the sample data.

\section{Research Methodology}

DEA measures efficiency by constructing a non-parametric frontier[4] using the linear programming methods. The original model was proposed by Charnes, Cooper and Rhodes (1978) based on the constant returns to scale (CRS) assumption with an input orientation. The methods have been widely applied in various industries. Traditional DEA model is used to compare the efficiency between decision making units (DMUs) during the same time period while ignoring the 
role of time. This can be misleading since the utilization of resources is always a dynamic context. The change of efficiency in air transport industry is always tracked over a period. Window analysis initiated by Charnes, etc. (1985) [5] brought in the concept of time into CCR-DEA model and use panel data instead of cross-sectional data for analysis.

Window DEA

The basic idea of Window DEA is to build windows during the study period according to a specified window width. Then each DMU is regarded as a different DMU in each of the reporting period. As such, a DMU is enabled to be compared with other DMUs as well as across different time periods. The results from panel data can indicate the dynamic movements of the efficiency. Because the number of DMUs is enlarged, this method can also improve the discrimination between DMUs. Most studies define the window size according to the length of study period.

Assume there are $I$ DMUs, each with $N$ inputs and $M$ outputs. Vectors ${ }^{x_{i}}$ and $y_{i}$ stand for the inputs and outputs of DMU $i$. Vectors $u$ and $v$ stand for the weights of outputs and inputs respectively. The input-oriented CCR-DEA model can be shown in equation (1).

$$
\begin{array}{ll}
\max _{u, v}\left(u y_{i} / v x_{i}\right) \\
\text { st. } \quad u y_{j} / v x_{j} \leq 1, \quad j=1,2, \cdots, I \\
& u, v \geq 0
\end{array}
$$

Super-efficiency

According to some studies on the application of DEA, limited number of DMUs may result in the situation that most of the DMUs position on the production frontier. So there exist many efficient DMUs with efficiency value of 1. Andersen etc.[6] built super-efficiency DEA model which enables the comparison between efficient DMUs. The basic skill of super-efficiency DEA is to remove the evaluated DMU from the efficiency frontier. For example, in fig. 1, the efficient frontier of DMU A, B, C and D is ABCD, which results in the efficiency values of four DMUs all equals 1. The result cannot be used to compare between the DMUs. In super-efficiency DEA model, when calculating the efficiency of DMU B, spot B is removed from the reference set and the efficient frontier changes from ABCD to ACD. So the results of the Super-efficiency DEA expel the situation of same efficiency value.

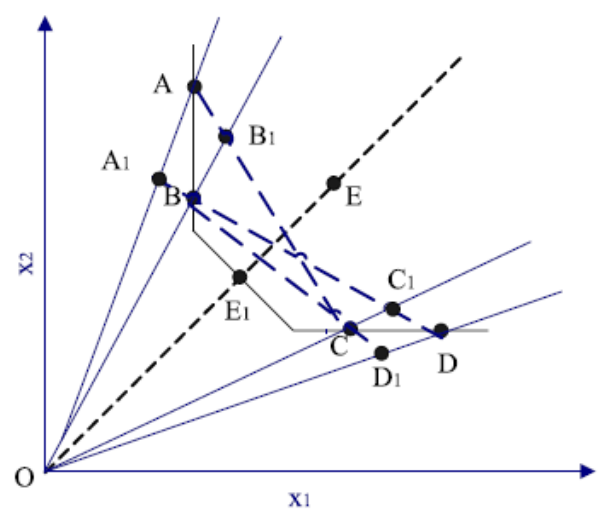

Figure 1. The Super DEA model

\section{Sample and Data}

The decision making units

There are now 22 civil pilot training institutions qualified of the CCAR-141 standard published by Civil Aviation Administration of China (CAAC). Among which Civil Aviation Flight University of China (CAFUC) acquired over $70 \%$ of the market share while other training institutions are newly built and with small scales. With a training history of over 60 years, CAFUC has obtained abundant flight training experience by operating in 4 bases with over 216 training aircrafts. The 
training situation of CAFUC can fully represent the industry. Therefore the paper performs an empirical study on training efficiency evaluation by choosing 4 training bases of CAFUC as DMUs, named as Base 1, Base 2, Base 3 and Base 4 respectively.

The paper selected 2011 to 2016 as the study period because during this period, China air transportation industry experienced significant development and presented serious problem of pilot shortage. Study on the efficiency of pilot training bases covering this period can reveal the potential of China's pilot training ability and help to solve the problem.

Based on the panel data of 4 DMUs and 6 years, the width of the window for window-DEA analysis is defined as 3 years. The number of DMUs is then enlarged to 16 (number of DMUs $\times$ number of window $=4 \times 4$ ).

The index system

With a consideration of the data availability, according to the characteristics of flight training, the indicator category of inputs and outputs is built in Table 1.

Table 1 The input and output index

\begin{tabular}{|l|l|l|}
\hline $\begin{array}{l}\text { Indicator } \\
\text { category }\end{array}$ & Indicator name & Calculation method \\
\hline $\begin{array}{l}\text { Input } \\
\text { indicator }\end{array}$ & $\begin{array}{l}\text { Flight instructors } \\
\text { Ground service people } \\
\text { Aircrafts }\end{array}$ & $\begin{array}{l}\text { No. of certificated instructors by the end of year } \\
\text { No. of registred ground service people by the end of year } \\
\text { No. of aircrafts by the end of year }\end{array}$ \\
\hline $\begin{array}{l}\text { Output } \\
\text { indicator }\end{array}$ & $\begin{array}{l}\text { Flight training time } \\
\text { Landing sorties } \\
\text { Graduated students }\end{array}$ & $\begin{array}{l}\text { Flight hours completed in the year, measured by hours } \\
\text { Landing sorties completed in the year, measured by times } \\
\text { No. of graduated students in the year }\end{array}$ \\
\hline
\end{tabular}

The data

Most data used in the research is from the investigations and interviews in CAFUC. Some data is collected from 《Civil Aviation Statistics》(2012-2017), government reports and university documents related to flight training.

\section{Results}

In this paper, an input-oriented CCR-DEA model is used to emphasize on operation management and resource utilization. We use the program PIM-DEA to solve the linear model built in section 3 .

Results of Window DEA with super-efficiency

Table 2 shows the efficiency values of DMU 1 in 4 windows as a sample.

Table 2 The super-efficiency value of Window-DEA

\begin{tabular}{|c|c|c|c|c|c|c|}
\hline \multirow{2}{*}{$\begin{array}{c}\text { Training } \\
\text { Base }\end{array}$} & \multicolumn{7}{|c|}{ Efficiency } \\
\cline { 2 - 7 } & 2011 & 2012 & 2013 & 2014 & 2015 & 2016 \\
\hline \multirow{3}{*}{$\begin{array}{c}\text { Base 1 } \\
\text { (DMU01) }\end{array}$} & 95.01 & 104.04 & 103.70 & & & \\
\cline { 2 - 7 } & & 95.21 & 97.88 & 106.63 & & \\
\cline { 2 - 7 } & & & 97.88 & 102.01 & 108.79 & \\
\cline { 2 - 7 } & & & & 101.77 & 101.14 & 103.66 \\
\hline
\end{tabular}

Comparison of efficiencies between 4 bases

To better compare the efficiencies between 4 bases, we calculated the average total factor productivity (TFP) efficiency of each base in every year as annual TFP efficiency and the statistics. It can be concluded that the overall efficiency of CAFUC soared sharply in 2012 then decreased in 2014. 
Table 3 Average TFP efficiency of 4 bases (2011-2016)

\begin{tabular}{|c|c|c|c|c|c|c|c|c|}
\hline \multirow{2}{*}{ Training base } & \multicolumn{6}{|c|}{ Annual TFP Efficiency } & \multicolumn{2}{|c|}{ Statistics } \\
\hline & 2011 & 2012 & 2013 & 2014 & 2015 & 2016 & Average efficiency & Standard deviation \\
\hline Base 1 & 95.01 & 99.63 & 99.82 & 103.47 & 104.97 & 103.66 & 101.09 & 13.60 \\
\hline Base 2 & 86.80 & 97.60 & 97.67 & 103.47 & 97.54 & 100.99 & 97.35 & 32.43 \\
\hline Base 3 & 91.68 & 106.75 & 87.48 & 65.18 & 111.17 & 102.22 & 94.08 & 280.63 \\
\hline Base 4 & 88.79 & 113.50 & 98.85 & 78.86 & 85.55 & 96.94 & 93.75 & 147.90 \\
\hline Average & 90.57 & 104.37 & 95.96 & 87.75 & 99.81 & 100.95 & 96.57 & 40.94 \\
\hline
\end{tabular}

According to the average efficiency in Table 4, Base 1 performed the highest efficiency during the study period; Base 2 ranks in the second position; Base 4 showed the lowest efficiency. Efficiency of Base 1 and Base 2 maintained stable during the years. The efficiency of Base 1 is even more stable and higher except in 2014, the efficiency of Base 1 and Base 2 reached the productivity frontier with the same efficiency value. The efficiency of Base 3 and Base 4 fluctuated significantly along the time, especially in year 2012 and 2014. This resulted in the standard deviation of Base 3 and Base 4 is extremely high compared to Base 1. The efficiency of Base 3 and Base 4 improved in 2012 and then declined sharply in 2014.

\section{Conclusions}

The paper used super-efficiency Window-DEA to build an input-oriented CCR model to analyze the training efficiency of China's civil pilot training efficiency. The training bases of CAFUC were chosen as 4 DMUs covering the year 2011 to 2016 as the research sample. The results show that there were significant fluctuations during the study period, primarily contributed by Base 3 and Base 4. Base 1 maintained the highest efficiency and most stable appearance. All the bases should pay attention to the technique innovation and management improvement to increase the efficiency. Besides, Base 3 and Base 4 should emphasis on the management stability to avoid fluctuation.

\section{References}

[1] Cornwell C, Schmidt P, Sickles RC. Production frontiers with cross-sectional and time-series variation in efficiency levels.[J]. Journal of econometrics, 1990, 46(1):185-200.

[2] Schefczyk, M. Operational performance of airlines: an extension of traditional measurement paradigms[J]. Strategic Management Journal, 1993, 14(4):301-317

[3] Michaelides, P. G., Belegri-Roboli, A., Karlaftis, M., \& Marinos, T. International air transportation carriers: evidence from SFA and DEA technical efficiency results[J]. European Journal of Transportation and Infrastructure Research, 2009, 4(9):347-362.

[4] Charnes A, Cooper W W, Rhodes E. Measuring the efficiency of decision making units[J]. European Journal of Operational Research, 1978, 2(6):429-444.

[5] Charnes A, Cooper W W. Preface to topics in data envelopment analysis[J]. Annals of Operations Research, 1985, 2(1):59-94.

[6] Anderson D. Energy Efficiency and the Economists: The Case for a Policy Based on Economic Principles[J]. Annual Review of Energy \& the Environment, 1995, 20(1):495-511. 